\title{
Synthesis, Structures, and Sorption Properties of Two New Metal- Organic Frameworks Constructed by the Polycarboxylate Ligand Derived from Cyclotriphosphazene
}

\author{
Jing-hua Han, Bing-qian Hu, Tangming Li, Hao Liang, Fan Yu,* Qiang Zhao, and Bao Li*
}

Cite This: ACS Omega 2021, 6, 23110-23116

Read Online

ABSTRACT: Solvothermal reactions of hexakis(4-carboxyphenoxy)cyclotriphospazene $\left(\mathrm{H}_{6} \mathrm{~L} 1\right)$ with copper ions in $\mathrm{DMF} / \mathrm{H}_{2} \mathrm{O}$ produced one complex, $\left\{\left[\mathrm{Cu}_{6}(\mathrm{~L} 1)_{2}(\mathrm{OH})\left(\mathrm{H}_{2} \mathrm{O}\right)_{3}\right] \text {.guest }\right\}_{n}$ (1), but with copper ions and auxiliary rigid 4,4-bipyridine (bpy) produced another new complex, namely, $\left\{\left[\mathrm{Cu}_{3}(\mathrm{~L} 1)(\text { bpy })\left(\mathrm{H}_{2} \mathrm{O}\right)_{6}\right] \text {-guest }\right\}_{n}$ (2). These complexes had been characterized by IR spectroscopy, elemental analysis, and X-ray structural determination. 1 exhibits a 3D anionic structure with the binodal 4,8 -connected network with Schläfli symbol $\left\{4^{6}\right\}_{2}\left\{4^{9}\right.$. $\left.6^{18} \cdot 8\right\}$, consisting of $\mathrm{Cu}_{6}$ clusters and $\mathrm{L} 1$ ligands. In contrast, complex 2 possesses a different $3 \mathrm{D}$ network with trinodal 3,4,6-c topology with Schläfli symbol $\left\{4 \cdot 6^{2}\right\}_{2}\left\{4^{2} \cdot 6^{6} \cdot 8^{5} \cdot 10^{2}\right\}\left\{6^{4} \cdot 8 \cdot 10\right\}$. In these two complexes, the semirigid hexacarboxylate ligands adopt distinct conformations to connect metal ions/clusters, which must be ascribed to the addition of the auxiliary rigid ligand in reaction systems. In addition, gas absorption properties of $\mathbf{1}$ and 2 including $\mathrm{CO}_{2}$ and $\mathrm{N}_{2}$ were further investigated.

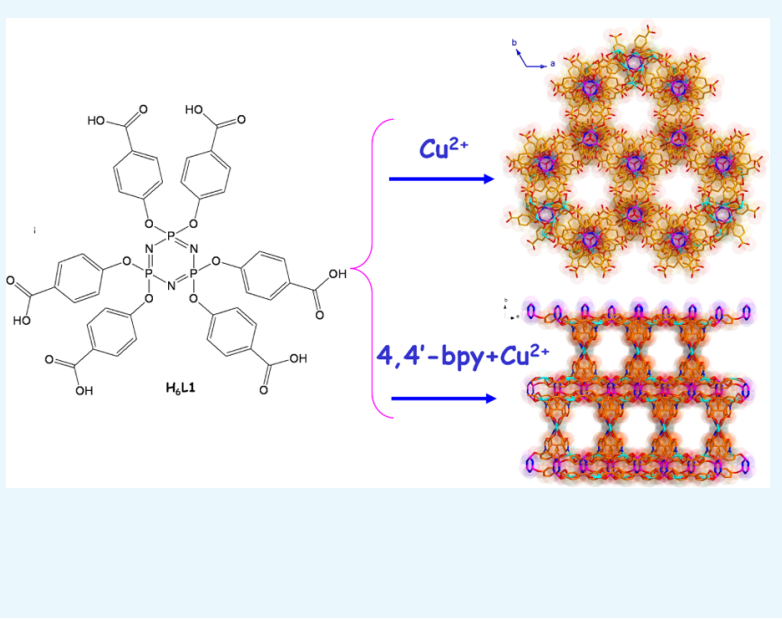

\section{INTRODUCTION}

Great attention focused on metal-organic frameworks (MOFs) originated from not only the aesthetics network but also their versatile potential applications. ${ }^{1-5}$ The composition of MOFs definitely contains metal nodes (ions/clusters) usually named secondary building units (SBUs) and organic spacer (strut or bridging linker). ${ }^{1-5}$ The rational construction of MOFs depends on versatile conditions. ${ }^{6-11}$ Therefore, controllable building of MOFs still poses a difficult challenge. In terms of rational assembly, proper utilization of organic linkers would be of one facile method to tune the topologies. ${ }^{12}$ The configuration and connection mode of the selected ligands are the key points to determine the final structure of MOFs. ${ }^{12}$ For example, the utilization of versatile rigid polycarboxylate ligands would determine the variable MOFs. ${ }^{13}$ However, coordination assemblies containing highly connected flexible carboxylate ligands are relatively rare. The narrow investigation must be ascribed to the limited selection regions of aromatic scaffolds and the corresponding synthesis conditions. Compared to the reported highly connected carboxylates referred to aromatic templates, our group explored a hexacarboxylate ligand, hexakis(4-carboxyphenoxy)cyclotriphosphazene $\left(\mathrm{H}_{6} \mathrm{~L} 1\right)$, derived from a renowned inorganic heterocyclic ring to act as the central scaffold and used to construct new MOFs.

The utilization of this polycarboxylate ligand was mainly based on several considerations: first, the substituents at the three phosphorus sites can be readily varied by appropriate nucleophilic substitutions; ${ }^{14}$ second, the polycarboxylate derivation possesses variable configuration originated from the six twisted carboxylate arms, which is very facile to result in versatile architectures under controllable synthesis conditions; and third, MOFs constructed by this polycarboxylate ligand that exhibits highly and variously connected mode might be endowed high thermostability and unexpected topological framework. In addition, with the aid of the rigid $\mathrm{N}$-containing ligands, the distinct topological framework would be also constructed compared to the mere reaction with various metal ions and this hexacarboxylate strut. ${ }^{15}$

With all the abovementioned considerations in mind, we tend to synthesize new MOFs assembled from metal ions and thus semirigid hexacarboxylate strut with/without the auxiliary rigid $\mathrm{N}$-containing linker. Herein, we reported the synthesis and characterization of two MOFs, namely, $\left\{\left[\mathrm{Cu}_{6}(\mathrm{~L} 1)_{2}(\mathrm{OH})\right.\right.$ $\left.\left(\mathrm{H}_{2} \mathrm{O}\right)_{3}\right]$.guest $\}_{n}(\mathbf{1})$ and $\left\{\left[\mathrm{Cu}_{3}(\mathrm{Ll}) \text { (bpy) }\left(\mathrm{H}_{2} \mathrm{O}\right)_{6}\right] \cdot \text { guest }\right\}_{n}$ (2). These new MOFs are characterized by elemental analysis, IR spectra, and X-ray crystallography.

Received: May 14, 2021

Accepted: August 11, 2021

Published: September 2, 2021 


\section{RESULTS AND DISCUSSION}

Synthesis of 1 and 2. Compound 1 was prepared under solvothermal conditions by heating an acid mixture of $\mathrm{Cu}\left(\mathrm{NO}_{3}\right)_{2} \cdot 3 \mathrm{H}_{2} \mathrm{O}$ and $\mathrm{H}_{6} \mathrm{~L} 1$ with a mole ratio of $10: 1$ in $\mathrm{DMF} / \mathrm{H}_{2} \mathrm{O}(\mathrm{v} / \mathrm{v}, 1 \mathrm{~mL} / 0.2 \mathrm{~mL})$ at $80{ }^{\circ} \mathrm{C}$ for 2 days. In contrast, compound $\mathbf{2}$ was prepared under solvothermal conditions by heating an identical mixture and solvent with the additional bpy at $100{ }^{\circ} \mathrm{C}$ for 5 days. Crystal data of $\mathbf{1}$ and $\mathbf{2}$ were gathered and are shown in Table S1. The relative qualified X-ray diffraction result of 1 after repeated attempts was given due to the weak diffraction intensity and small size of the crystalline sample. However, the clear structure could be observed after careful dissolution, which could also be verified by the XRD and EA results (Figure 1).

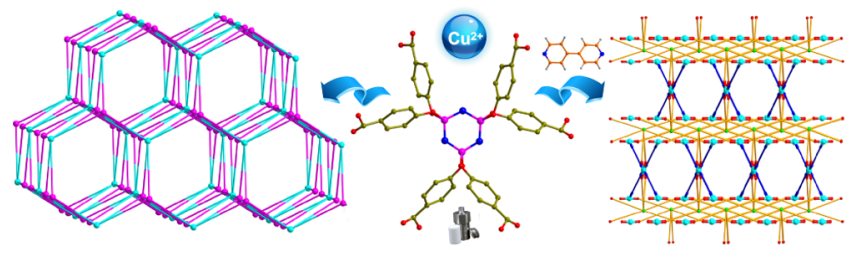

Figure 1. Reaction route of $\mathbf{1}$ and 2.

Crystal Structure of 1. A single-crystal X-ray diffraction study performed on compound $\mathbf{1}$ reveals that it is a high symmetric three-dimensional (3D) framework, crystallized in trigonal space group $P \overline{3} c 1$. The asymmetric unit of 1 contains two copper ions, one coordinated water, and two types of $1 / 3$ ligand and hydroxyl (Figure S3). The $\mathrm{Cu}(1)$ atom adapts square planar geometry, coordinated by four oxygen atoms from four carboxylates in three types of the connection mode: mono-dentate, syn-syn $\mu_{2}{ }^{\mathrm{b}}$ bridging, and syn-syn-anti $\mu_{3}-\eta^{2}: \eta^{1}$ tridentate coordination mode, as shown in Figure 2a. In contrast, the $\mathrm{Cu}(2)$ atom adapts a slightly distorted trigonal bipyramid with the $\tau_{5}$ parameter of 0.3 , whose equatorial vertices comprised three $\mathrm{O}$ atoms separately from different carboxyl of L1 in two coordination modes: syn-syn $\mu_{2}{ }^{\mathrm{b}}$ bridging and syn-syn-anti $\mu_{3}-\eta^{2}: \eta^{1}$ tridentate coordination mode, and the axial positions are occupied by two oxygen atoms separately from one coordinated aqua molecule and $\mu_{3}$ hydroxyl group (Figure 3). $\mathrm{Cu}(1)$ and $\mathrm{Cu}(2)-\mathrm{O}$ bond lengths range from $1.920(8)$ to $2.430(7) \AA$, similar to the typical $\mathrm{Cu}^{\mathrm{II}}-$
$\mathrm{O}$ bond lengths. Three $\mathrm{Cu}(2)$ atoms are interlinked by the oxygen atom of the $\mu_{3}$-hydroxyl group, which are further connected reciprocally by one oxygen atom of the tri-dentate carboxyl to form the tri-nuclear core. Moreover, three $\mathrm{Cu}(1)$ atoms are interconnected to $\mathrm{Cu}(2)$ atoms by two kinds of carboxylate groups (three syn-syn carboxyl from one hexacarboxylate ligand and three tridentate carboxyl from another one) to form the hexanuclear copper SBU (Figure 2a). Three coordinated aqua molecules on $\mathrm{Cu}(2)$ atoms are decorated on the surface of the tri-nuclear core to fulfill the coordination environment. Thus, planar metal-cluster-based SBUs are extended by eight hexacarboxylate ligands through six mono-dentate carboxylate groups of different ligands at the parallel plane of Cu6 SBU and six bridging carboxyls separately from two hexacarboxylate ligands along the perpendicular direction of Cu6 SBU, as shown in Figure $2 \mathrm{~b}$.

In $\mathbf{1}$, there are two distinct connection modes of hexacarboxylate ligands, which are connecting four hexanuclear copper SBUs into an infinite 3D anionic open framework. Large cavities with a diameter of $15.37 \times 9.06 \AA$ were embedded in the whole structure and arranged along the $c$ axis (Figure 4), which might be filled with the counter-cation. The uncoordinated oxygen atoms of mono-dentate carboxyls and coordinated aqua molecules point toward the center of the pores, which might play an important role in the field of gas sorption or catalysis. The solvent-accessible volume in the dehydrated structure of $\mathbf{1}$ is about $45.4 \%$, calculated by PLATON routine. Considering the copper SBUs and hexacarboxylate ligands as eight- and four-connecting nodes, respectively, 1 topologically possesses a 4,8-connected 2-nodal net with stoichiometry $(4-c)_{2}(8-c)$ and the point (Schläfli) symbol $\left\{4^{6}\right\}_{2}\left\{4^{9} \cdot 6^{18} \cdot 8\right\}$ calculated with TOPOS software (Figure 5), ${ }^{16}$ which has been reported as $4,8 \mathrm{~T} 11$ topological type. The connection of hexanuclear clusters and hexacarboxylate ligands is responsible for the generation of different topologies compared to the structure consisted of paddlewheel $\mathrm{Cu}_{2}$ cluster and hexacarboxylate ligands.

Crystal Structure of 2 . The reaction of the same copper salt and hexacarboxylate ligands with the auxiliary $\mathrm{N}$ containing pillar, bpy, has produced another MOF 2 which also exhibit a three-dimensional (3D) framework. 2 crystallizes in monoclinic space group $C 2 / c$, along with one copper ion named $\mathrm{Cu}(1)$, one bpy pillar, three coordinated aqua molecules, and one-half of copper ion named $\mathrm{Cu}(2)$ and

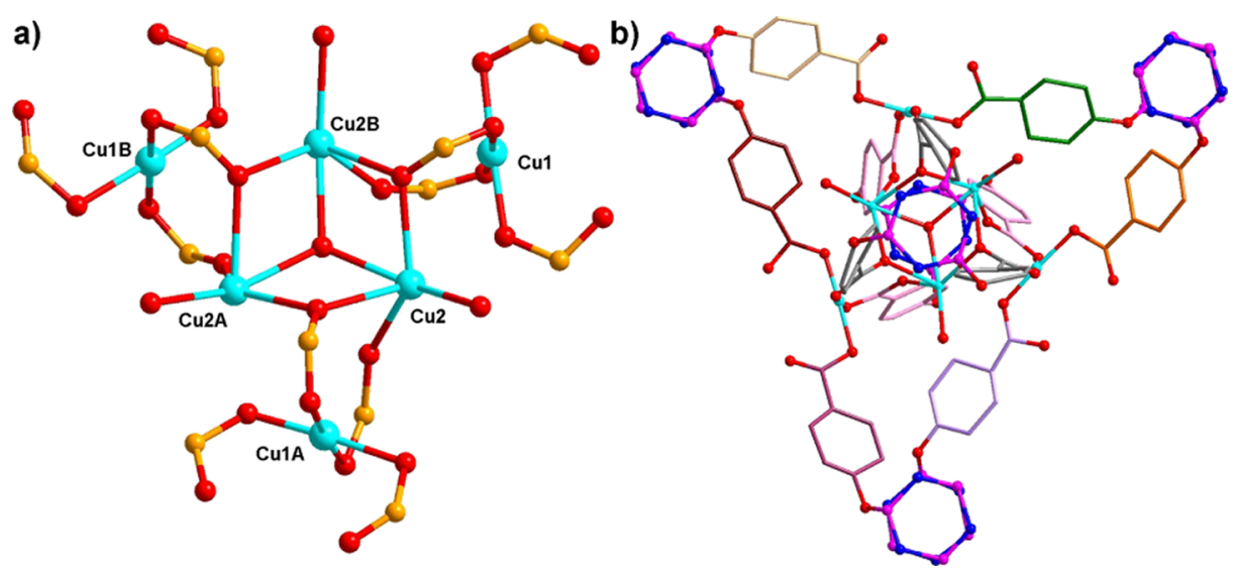

Figure 2. Perspective of the hexanuclear copper SBU (a) and eight-connected mode of $\mathrm{Cu}_{6} \mathrm{SBU}$ (each colorful carbon atoms represents one pendant of the L1 ligand) (b). Symmetric code: A, $-x+y,-x-1, z$ and $\mathrm{B},-y-1, x-y-1, z$. 

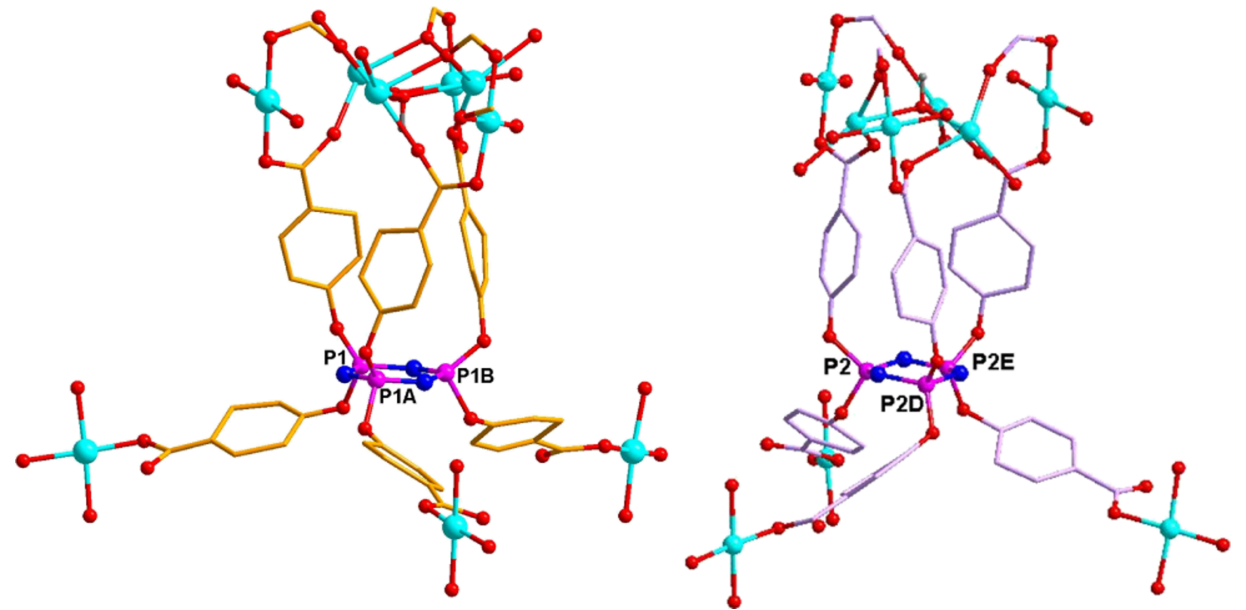

Figure 3. Connection modes of two types of four-connected hexacarboxylate ligands in 1. For clarity, all hydrogen atoms are omitted. Symmetric code: $\mathrm{A},-x+y+1,-x, z ; \mathrm{B},-y, x-y-1, z ; \mathrm{D},-x+y,-x-1, z$; and $\mathrm{E},-y-1, x-y-1, z$.

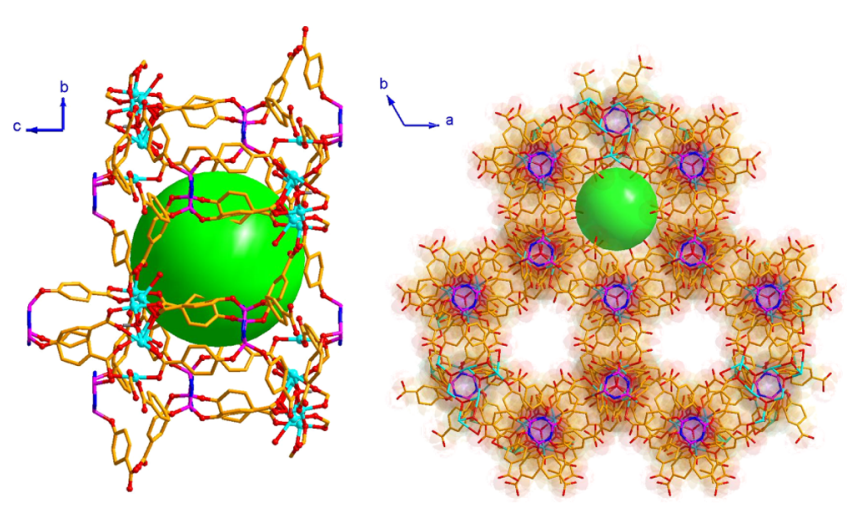

Figure 4. Partial view of cavity and the 3D crystal structure of 1 , along with the $1 \mathrm{D}$ channels.

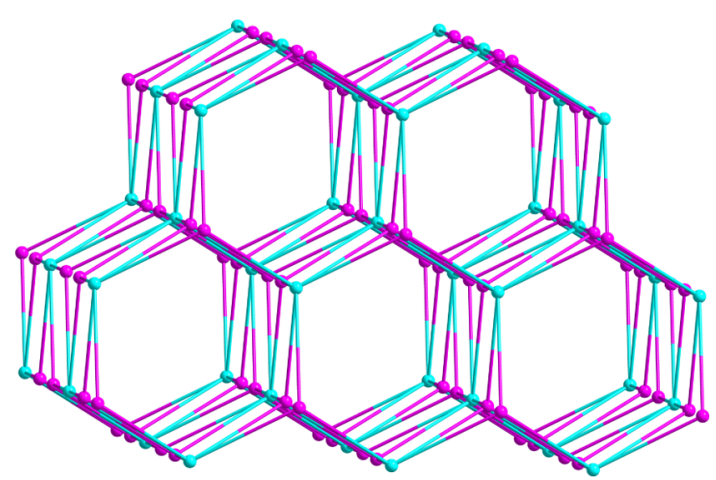

Figure 5. Perspective view of the $4,8 \mathrm{~T} 11$ topological structure of 1 (the blue and purple balls represent the eight-connected $\mathrm{Cu}_{6}$ SBUs and four-connected L1 ligands, respectively).

ligand in an asymmetric unit, shown in Figure S4. The $\mathrm{Cu}(1)$ atom adapts a square-pyramidal with a $\tau_{5}$ parameter of 0.07 . The basal plane is constructed by one pyridyl $\mathrm{N}(\mathrm{N} 3)$ atoms of bpy and three oxygen atoms separately from two mono-dentate carboxyls and one coordinated water, while the apical position is occupied by another coordinated aqua molecule, as shown in Figure 6a. In contrast, the $\mathrm{Cu}(2)$ atom adapts a slightly distorted octahedral environment. The equatorial vertices consist of two $\mathrm{O}$ atoms separately from different monodentate carboxyl of L1 and two nitrogen atoms (N3) from two

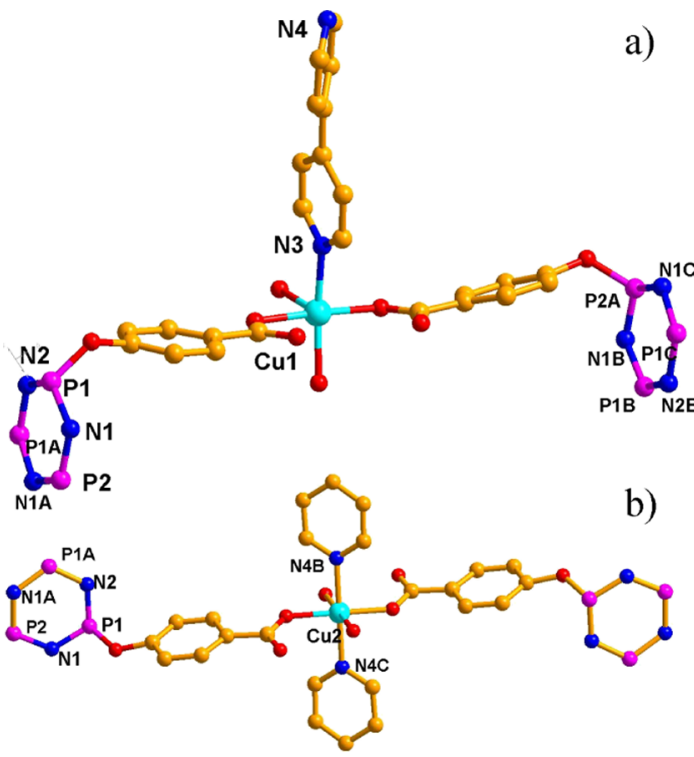

Figure 6. Coordination environment of copper ions in 2. For clarity, all hydrogen atoms are omitted. Symmetric code: (a) $\mathrm{A},-x+1, y,-z$ $+1 / 2 ; \mathrm{B},-x+2,-y,-z+1$; C, $x+1,-y, z+1 / 2$ and (b) A, $-x+1$, $y, z+1 / 2 ; \mathrm{B}, x-1 / 2,-y+1 / 2, z-1 / 2 ; \mathrm{C},-x+1, y,-z+3 / 2$.

byp ligands, and the axial positions are occupied by two oxygen atoms from two coordinated aqua molecules, as shown in Figure $6 \mathrm{~b}$. The $\mathrm{Cu}-\mathrm{O}$ and $-\mathrm{N}$ bond lengths range from 1.945(3) and 2.452(4) $\AA$, similar to the many previous reported $\mathrm{Cu}^{\mathrm{II}}-\mathrm{O}$ and-N bond lengths.

In 2 , the center-symmetric hexacarboxylate ligands connect six copper ions by its mono-dentate carboxylate group, as shown in Figure 7. Each extended ligand connects four copper ions. As such, all of the hexacarboxylate ligands serve as sixconnected bridges to link different metallic nodes into an infinite 3D crystal structure, which are further stabilized by the rigid bpy pillars located along the $b$ axial direction, shown in Figure 8. 1D channels with a diameter of $16.25 \times 12.21 \AA$ A were embedded in the whole structure and arranged along the $c$ axis (Figure 7). The coordinated aqua molecules on copper ions also point toward the center of pores. The solvent-accessible volume in 2 is about $42.0 \%$, calculated by PLATON routine. Considering the two kinds of copper ions, hexacarboxylate 


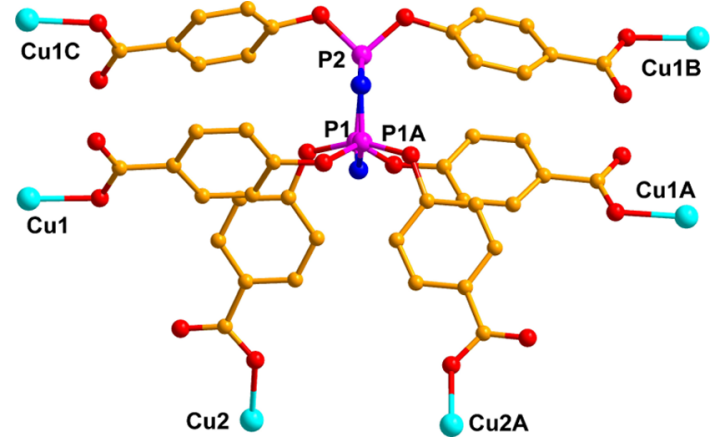

Figure 7. Coordination environments of the six-connected polycarboxylate ligand. For clarity, all hydrogen atoms are omitted. Symmetric code: A, $-x+1, y,-z+1 / 2$; B, $x-1,-y, z-1 / 2$; and C, $-x+2,-y,-z+1$.

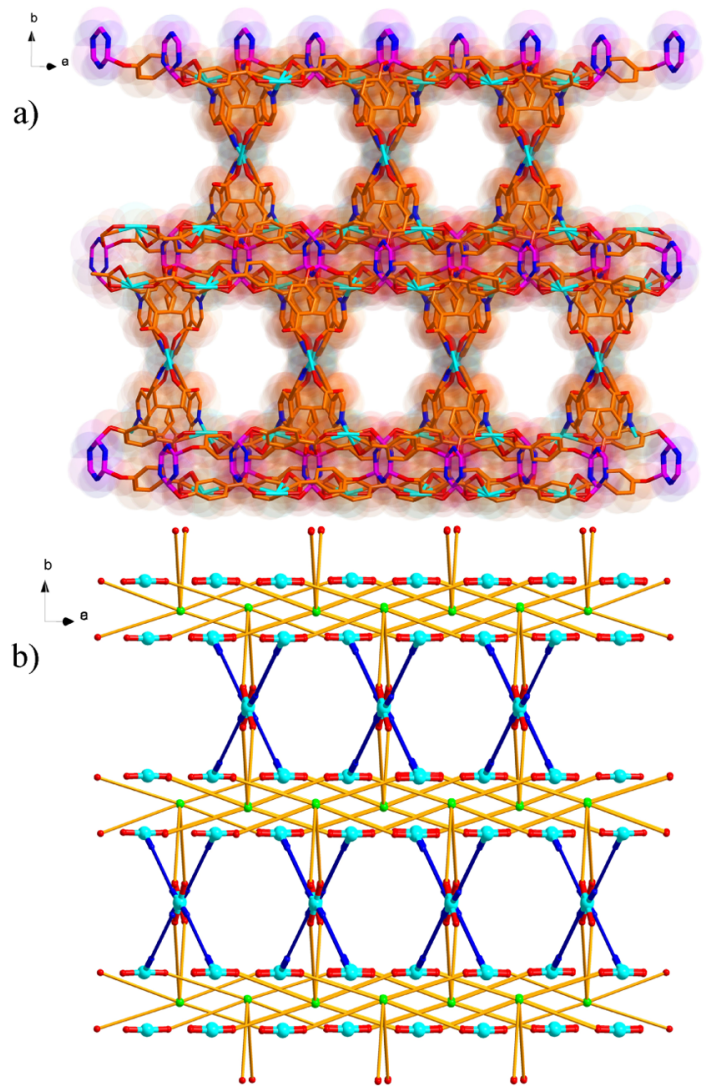

Figure 8. (a) Partial view of the 3D structure of 2 showing the $1 \mathrm{D}$ channels along the crystallographic $c$-axis direction and (b) view of the topological structure of $\mathbf{2}$ (blue and green balls represent the fourconnected $\mathrm{Cu}$ ions and six-connected L1 ligands, respectively; the deep-blue lines represent the linear linker, byp).

ligands, and bpy as three-, four-, six-, and two-connecting nodes, respectively, the overall structure of 2 topologically possesses a 3,4,6-connected 4-nodal net with stoichiometry (3c) ${ }_{2}(4-c)(6-c)$ and the Schläfli symbol $\left\{4 \cdot 6^{2}\right\}_{2}\left\{4^{2} \cdot 6^{6} \cdot 8^{5} \cdot 10^{2}\right\}\left\{6^{4}\right.$. $8 \cdot 10\}$ calculated with TOPOS software (Figure 8). ${ }^{16}$ Thus, the topological type has not been found in the database according to the routine of TOPOS.

Thermal Stability. Thermal stability of 1-2 had been further examined by thermogravimetric analyses (TGAs) by the utilization of crystalline samples under a $\mathrm{N}_{2}$ atmosphere (Figure 9). Observed from the TGA curve, 1 undergoes

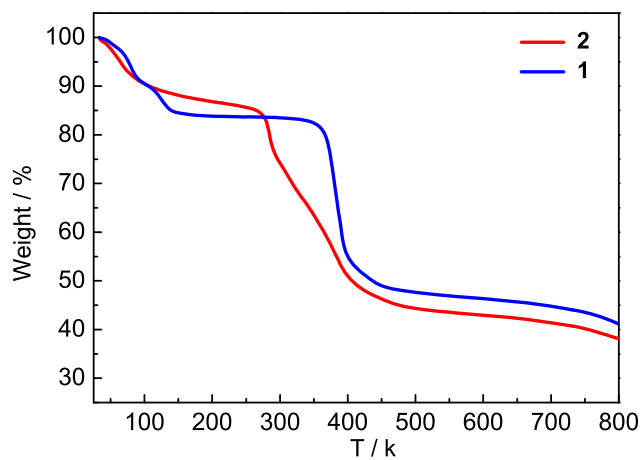

Figure 9. TGA curves of 1-2.

dehydration before $150^{\circ} \mathrm{C}$ and decomposition around $360^{\circ} \mathrm{C}$. For 2, the weight loss from 30 to $130^{\circ} \mathrm{C}$ should be ascribed to the loss of lattice water molecules, and the decomposition began around $300{ }^{\circ} \mathrm{C}$. The high connection mode of the hexanuclear clusters must be the main reason for the higher thermal stability of $\mathbf{1}$ compared to $\mathbf{2}$.

Sorption Properties. In order to validate the pores of the porous samples of $\mathbf{1}$ and 2 , the gas sorption experiments of hydrogen and $\mathrm{CO}_{2}$ have been carried out. The desolvated samples were produced via immersing in methanol and acetone. Then, the solid sample was vacuum-dried at room temperature and $120{ }^{\circ} \mathrm{C}$ overnight, respectively. Observed from the adsorption curves, the typical type-I adsorption isotherms with no significant hysteresis between sorption and desorption traces had been presented, indicating the microporous materials for 1 . The adsorption amount of $\mathrm{N}_{2}$ at $77 \mathrm{~K}$ is $87 \mathrm{~cm}^{3} / \mathrm{g}$, along with the calculated Brunauer-Emmett-Teller (BET) and Langmuir surface areas of 275 and $367 \mathrm{~m}^{2} / \mathrm{g}$. Comparably, the desolvated samples of 1 continuously exhibit the low-pressure $\mathrm{CO}_{2}$ adsorption via volumetric gas adsorption measurements, illustrating the fully reversible adsorption behavior. The approximate $29 \mathrm{~cm}^{3} / \mathrm{g} \mathrm{CO}_{2}$ uptake had been observed under $273 \mathrm{~K}$ and 1 bar (Figure 10). The XRD pattern

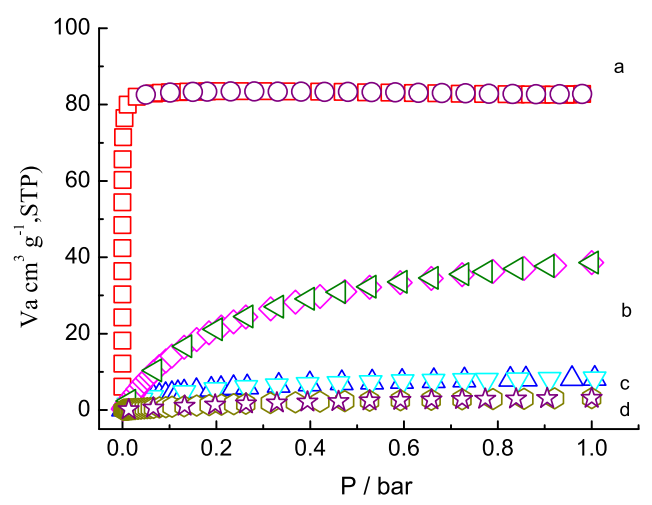

Figure 10. Sorption isotherms for 1 and 2: (a) $\mathrm{N}_{2}$ (1) at $77 \mathrm{~K}$; (b) $\mathrm{CO}_{2}(1)$ at $273 \mathrm{~K} ;(\mathrm{C}) \mathrm{N}_{2}(2)$ at $77 \mathrm{~K}$; and (D) $\mathrm{CO}_{2}(2)$ at $273 \mathrm{~K}$.

of samples after the adsorption experiments is similar to the fresh sample and simulated pattern (Figure S1), which also illustrates the stable framework for $\mathbf{1}$. However, the porous structure of 2 collapsed during the procession of desolvent, confirmed by the XRD spectra and gas absorption experimental measurements. 


\section{CONCLUSIONS}

In summary, two MOFs using the flexible hexacarboxylate ligand derived from a renowned inorganic heterocyclic cyclotriphosphazene have been successfully synthesized and structurally characterized. The structural results show that using the flexible ligand would be of a good approach to produce diversity in final structures. 1 exhibits a $3 \mathrm{D}$ anionic structure incorporating with hexanuclear $\mathrm{Cu}^{\mathrm{II}} \mathrm{SBUs}$ and two kinds of hexacarboxylate ligands, while 2 has a 3D topology with a $1 \mathrm{D}$ channel resided in the structure. The highly connected hexanuclear SUBs must be the main reason for the higher thermal stability compared $\mathbf{1}$ to 2 , as well as the stable desolvated structure of $\mathbf{1}$ for the application of gas sorption.

\section{EXPERIMENTAL SECTION}

Synthesis of $\left\{\left[\mathrm{Cu}_{6}(\mathrm{~L} 1)_{2}(\mathrm{OH})\left(\mathrm{H}_{2} \mathrm{O}\right)_{3}\right] \cdot \text { Guest }\right\}_{n}$ (1). A mixture of $\mathrm{Cu}\left(\mathrm{NO}_{3}\right)_{3} \cdot 3 \mathrm{H}_{2} \mathrm{O}(30 \mathrm{mg})$ and $\mathrm{H}_{6} \mathrm{Ll}(10 \mathrm{mg})$ was dissolved in $15 \mathrm{~mL}$ of $\mathrm{DMF} / \mathrm{H}_{2} \mathrm{O}(1: 2, \mathrm{v} / \mathrm{v})$, and then, the $\mathrm{pH}$ value was adjusted to $2-3$. The final mixture was heated at $80{ }^{\circ} \mathrm{C}$ under autogenous pressure for $48 \mathrm{~h}$ in 10 Parr Teflonlined stainless-steel vessels and then cooled to room temperature. The resulting solution was allowed to stand undisturbedly from which square-like crystals were obtained. The crystals were collected together, washed with the mother liquid, and dried under ambient conditions. Yield of the reaction was ca. $41 \%$ based on $\mathrm{H}_{6} \mathrm{~L} 1$. Anal. Calcd for dehydrated $\mathrm{C}_{84} \mathrm{H}_{55} \mathrm{Cu}_{6} \mathrm{~N}_{6} \mathrm{O}_{40} \mathrm{P}_{6}: \mathrm{C}, 42.83 \%, \mathrm{H}, 2.35 \%, \mathrm{~N}$, $3.57 \%$; found $\mathrm{C}, 42.03 \%, \mathrm{H}, 3.02 \%, \mathrm{~N}, 4.07 \%$. For fresh sample: C, $41.89 \%, \mathrm{H}, 3.51 \%, \mathrm{~N}, 4.36 \%$. Calculated with EA and TGA data, the whole formula of 1 should be $\left\{\left(\mathrm{C}_{2} \mathrm{H}_{6} \mathrm{NH}\right)\right.$. $\left.\left[\mathrm{Cu}_{6}(\mathrm{~L} 1)_{2}(\mathrm{OH})\left(\mathrm{H}_{2} \mathrm{O}\right)_{3}\right] \cdot \mathrm{DMF} \cdot\left(\mathrm{H}_{2} \mathrm{O}\right)_{5}\right\}_{n}$. IR $\left(\mathrm{KBr}, \mathrm{cm}^{-1}\right)$ : 3481, 1603, 1543, 1420, 1384, 1210, 1159, 966, 790.

Synthesis of $\left\{\left[\mathrm{Cu}_{3}(\mathrm{~L} 1) \text { (bpy) }\left(\mathrm{H}_{2} \mathrm{O}\right)_{6}\right] \cdot \text { Guest }\right\}_{n}$ (2). The synthesis process was very similar to 1 except adding 4,4bipyridine $20 \mathrm{mg}$ in the reaction system, adjusting the $\mathrm{pH}$ range located in 4-5 for $120 \mathrm{~h}$. Square-like crystals were directly obtained, and crystals were filtered off, washed with the mother liquid, and dried under ambient conditions. Yield of the reaction was ca. $23 \%$ based on $\mathrm{H}_{6} \mathrm{~L} 1$. Calcd for dehydrated $\mathrm{C}_{62} \mathrm{H}_{52} \mathrm{Cu}_{3} \mathrm{~N}_{7} \mathrm{O}_{24} \mathrm{P}_{3}: \mathrm{C}, 47.65 \%, \mathrm{H}, 3.35 \%, \mathrm{~N}$, $6.27 \%$; found $\mathrm{C}, 46.98 \%, \mathrm{H}, 3.03 \%, \mathrm{~N}, 6.87 \%$. For the fresh sample: C, $45.65 \%, \mathrm{H}, 3.05 \%, \mathrm{~N}, 4.74 \%$. Calculated with EA and TGA data, the whole formula of 2 should be $\left\{\left[\mathrm{Cu}_{3}(\mathrm{~L} 1)\right.\right.$ (bpy) $\left.\left.\left(\mathrm{H}_{2} \mathrm{O}\right)_{6}\right] \cdot\left(\mathrm{H}_{2} \mathrm{O}\right)_{8}\right\}_{n}$. IR $\left(\mathrm{KBr}, \mathrm{cm}^{-1}\right): 3418,1604,1540$, 1420, 1384, 1211, 1159, 967, 790.

\section{ASSOCIATED CONTENT}

\section{s) Supporting Information}

The Supporting Information is available free of charge at https://pubs.acs.org/doi/10.1021/acsomega.1c02492.

Detailed experimental sections, thermal spectra, and XRD spectrum of 1-2 (PDF).

(CIF)

(CIF)

\section{AUTHOR INFORMATION}

\section{Corresponding Authors}

Fan Yu - Key Laboratory of Optoelectronic Chemical Materials and Devices of Ministry of Education, School of Chemical and Environmental Engineering, Jianghan University, Wuhan, Hubei 430056, People's Republic of China; School of Chemistry and Chemical Engineering,
Hubei Key Laboratory of Bioinorganic Chemistry \& Materia Medica, Huazhong University of Science and Technology, Wuhan, Hubei 430074, P. R. China; Email: yufan0714@ 163.com

Bao Li - School of Chemistry and Chemical Engineering, Hubei Key Laboratory of Bioinorganic Chemistry \& Materia Medica, Huazhong University of Science and Technology, Wuhan, Hubei 430074, P. R. China; ㅇoㅇid.org/00000003-1154-6423; Email: libao@hust.edu.cn

\section{Authors}

Jing-hua Han - Key Laboratory of Optoelectronic Chemical Materials and Devices of Ministry of Education, School of Chemical and Environmental Engineering, Jianghan University, Wuhan, Hubei 430056, People's Republic of China

Bing-qian Hu - Key Laboratory of Optoelectronic Chemical Materials and Devices of Ministry of Education, School of Chemical and Environmental Engineering, Jianghan University, Wuhan, Hubei 430056, People's Republic of China

Tangming Li - Key Laboratory of Optoelectronic Chemical Materials and Devices of Ministry of Education, School of Chemical and Environmental Engineering, Jianghan University, Wuhan, Hubei 430056, People's Republic of China

Hao Liang - Key Laboratory of Optoelectronic Chemical Materials and Devices of Ministry of Education, School of Chemical and Environmental Engineering, Jianghan University, Wuhan, Hubei 430056, People's Republic of China

Qiang Zhao - School of Chemistry and Chemical Engineering, Hubei Key Laboratory of Bioinorganic Chemistry \& Materia Medica, Huazhong University of Science and Technology, Wuhan, Hubei 430074, P. R. China; ㅇorcid.org/00000002-0643-5916

Complete contact information is available at:

https://pubs.acs.org/10.1021/acsomega.1c02492

\section{Notes}

The authors declare no competing financial interest.

\section{ACKNOWLEDGMENTS}

This work was supported by the financial supports of the National Science Foundation of China (21971078), the Frontier Project of Application Foundation of Wuhan Science and Technology Bureau of China (grant no. 2020010601012201), and the Fundamental Research Funds for the Central Universities (2019kfyRCPY071 and 2019kfyXKJC009). We gratefully acknowledge the Analytical and Testing Center, Huazhong University of Science and Technology, for analysis and spectral measurements. We also thank the staffs from BL17B beamline of the National Center for Protein Sciences Shanghai (NCPSS) at Shanghai Synchrotron Radiation Facility, for assistance during data collection.

\section{REFERENCES}

(1) (a) Park, J.; Xu, M.; Li, F.; Zhou, H.-C. 3D Long-Range Triplet Migration in a Water-Stable Metal-Organic Framework for Upconversion-Based Ultralow-Power in Vivo Imaging. J. Am. Chem. Soc. 2018, 140, 5493-5499. (b) Paille, G.; Gomez-Mingot, M.; RochMarchal, C.; Lassalle-Kaiser, B.; Mialane, P.; Fontecave, M.; Mellot- 
Draznieks, C.; Dolbecq, A. A Fully Noble Metal-Free Photosystem Based on Cobalt-Polyoxometalates Immobilized in a Porphyrinic Metal-Organic Framework for Water Oxidation. J. Am. Chem. Soc. 2018, 140, 3613-3618. (c) Goswami, S.; Ray, D.; Otake, K.-i.; Kung, C.-W.; Garibay, S. J.; Islamoglu, T.; Atilgan, A.; Cui, Y.; Cramer, C. J.; Farha, O. K.; Hupp, J. T. A porous, electrically conductive hexazirconium(iv) metal-organic framework. Chem. Sci. 2018, 9, 44774482. (d) Hoskins, B. F.; Robson, R. Design and construction of a new class of scaffolding-like materials comprising infinite polymeric frameworks of 3D-linked molecular rods. A reappraisal of the zinc cyanide and cadmium cyanide structures and the synthesis and structure of the diamond-related frameworks $[\mathrm{N}(\mathrm{CH} 3) 4][\mathrm{CuIZnII-}$ (CN)4] and $\mathrm{CuI}\left[4,4^{\prime}, 4^{\prime \prime}, 4^{\prime \prime \prime}\right.$-tetracyanotetraphenylmethane]BF4.xC6H5NO2. J. Am. Chem. Soc. 1990, 112, 1546-1554.

(2) (a) He, H.; Sun, Q.; Gao, W.; Perman, J. A.; Sun, F.; Zhu, G.; Aguila, B.; Forrest, K.; Space, B.; Ma, S. A Stable Metal-Organic Framework Featuring a Local Buffer Environment for Carbon Dioxide Fixation. Angew. Chem., Int. Ed. 2018, 57, 4657-4662. (b) Sun, X.; Yao, S.; Yu, C.; Li, G.; Liu, C.; Huo, Q.; Liu, Y. An ultrastable ZrMOF for fast capture and highly luminescence detection of Cr2O72simultaneously in an aqueous phase. J. Mater. Chem. A 2018, 6, 63636369. (c) Sun, J.-K.; Yang, X.-D.; Yang, G.-Y.; Zhang, J. Bipyridinium derivative-based coordination polymers: From synthesis to materials applications. Coord. Chem. Rev. 2019, 378, 533-560.

(3) (a) Gu, Z.-G.; Zhang, J. Epitaxial growth and applications of oriented metal-organic framework thin films. Coord. Chem. Rev. 2019, 378, 513-532. (b) Bao, Z.; Xie, D.; Chang, G.; Wu, H.; Li, L.; Zhou, W.; Wang, H.; Zhang, Z.; Xing, H.; Yang, Q.; Zaworotko, M. J.; Ren, Q.; Chen, B. Fine Tuning and Specific Binding Sites with a Porous Hydrogen-Bonded Metal-Complex Framework for Gas Selective Separations. J. Am. Chem. Soc. 2018, 140, 4596-4603. (c) Wu, J.; $\mathrm{Li}, \mathrm{S}$.; Wei, H. Integrated nanozymes: facile preparation and biomedical applications. Chem. Commun. 2018, 54, 6520-6530.

(4) (a) Mon, M.; Bruno, R.; Ferrando-Soria, J.; Armentano, D.; Pardo, E. Metal-organic framework technologies for water remediation: towards a sustainable ecosystem. J. Mater. Chem. A 2018, 6, 4912-4947. (b) Chen, Y.-Z.; Zhang, R.; Jiao, L.; Jiang, H.-L. Metalorganic framework-derived porous materials for catalysis. Coord. Chem. Rev. 2018, 362, 1-23.

(5) (a) Liao, P.-Q.; Shen, J.-Q.; Zhang, J.-P. Metal-organic frameworks for electrocatalysis. Coord. Chem. Rev. 2018, 373, 2248. (b) Jiang, H.; Liu, X.-C.; Wu, Y.; Shu, Y.; Gong, X.; Ke, F.-S.; Deng, H. Metal-Organic Frameworks for High Charge-Discharge Rates in Lithium-Sulfur Batteries. Angew. Chem., Int. Ed. 2018, 57, 3916-3921. (c) Li, Q.; Wu, N.; Li, J.; Wu, D.; Li, Y. AminoFunctionalized Water-Stable Metal-Organic Framework for Enhanced $\mathrm{C} 2 \mathrm{H} 2 / \mathrm{CH} 4$ Separation Performance. Inorg. Chem. 2020, 59, 26312635.

(6) (a) Lan, G.; Ni, K.; Xu, Z.; Veroneau, S. S.; Song, Y.; Lin, W. Nanoscale Metal-Organic Framework Overcomes Hypoxia for Photodynamic Therapy Primed Cancer Immunotherapy. J. Am. Chem. Soc. 2018, 140, 5670-5673. (b) He, Y.; Chen, F.; Li, B.; Qian, G.; Zhou, W.; Chen, B. Porous metal-organic frameworks for fuel storage. Coord. Chem. Rev. 2018, 373, 167-198. (c) Wu, S.; Lin, Y.; Liu, J.; Shi, W.; Yang, G.; Cheng, P. Rapid Detection of the Biomarkers for Carcinoid Tumors by a Water Stable Luminescent Lanthanide Metal-Organic Framework Sensor. Adv. Funct. Mater. 2018, 28, 1707169.

(7) (a) Yin, Z.; Wan, S.; Yang, J.; Kurmoo, M.; Zeng, M.-H. Recent advances in post-synthetic modification of metal-organic frameworks: New types and tandem reactions. Coord. Chem. Rev. 2019, 378, 500512. (b) Yang, Q. Y.; Lama, P.; Sen, S.; Lusi, M.; Chen, K. J.; Gao, W. Y.; Shivanna, M.; Pham, T.; Hosono, N.; Kusaka, S.; Perry, J. J.; Ma, S.; Space, B.; Barbour, L. J.; Kitagawa, S.; Zaworotko, M. J. Reversible Switching between Highly Porous and Nonporous Phases of an Interpenetrated Diamondoid Coordination Network That Exhibits Gate-Opening at Methane Storage Pressures. Angew. Chem., Int. Ed. 2018, 57, 5684-5689.
(8) (a) Yu, Y.; Shi, Y.; Zhang, B. Synergetic Transformation of Solid Inorganic-Organic Hybrids into Advanced Nanomaterials for Catalytic Water Splitting. Acc. Chem. Res. 2018, 51, 1711-1721. (b) La, D. D.; Bhosale, S. V.; Jones, L. A.; Bhosale, S. V. Tetraphenylethylene-Based AIE-Active Probes for Sensing Applications. ACS Appl. Mater. Interfaces 2018, 10, 12189-12216. (c) Zhao, M.; Huang, Y.; Peng, Y.; Huang, Z.; Ma, Q.; Zhang, H. Twodimensional metal-organic framework nanosheets: synthesis and applications. Chem. Soc. Rev. 2018, 47, 6267-6295. (d) Ma, Y.-J.; Hu, J.-X.; Han, S.-D.; Pan, J.; Li, J.-H.; Wang, G.-M. Manipulating On/Off Single-Molecule Magnet Behavior in a Dy(III)-Based Photochromic Complex. J. Am. Chem. Soc. 2020, 142, 2682-2689. (e) Liu, A.-J.; Xu, F.; Han, S.-D.; Pan, J.; Wang, G.-M. Mixed-Ligand Strategy for the Construction of Photochromic Metal-Organic Frameworks Driven by Electron-Transfer Between Nonphotoactive Units. Cryst. Growth Des. 2020, 20, 7350-7355.

(9) (a) Gui, D.; Dai, X.; Tao, Z.; Zheng, T.; Wang, X.; Silver, M. A.; Shu, J.; Chen, L.; Wang, Y.; Zhang, T.; Xie, J.; Zou, L.; Xia, Y.; Zhang, J.; Zhang, J.; Zhao, L.; Diwu, J.; Zhou, R.; Chai, Z.; Wang, S. Unique Proton Transportation Pathway in a Robust Inorganic Coordination Polymer Leading to Intrinsically High and Sustainable Anhydrous Proton Conductivity. J. Am. Chem. Soc. 2018, 140, 6146-6155. (b) Cai, L.-X.; Li, S.-C.; Yan, D.-N.; Zhou, L.-P.; Guo, F.; Sun, Q.-F.; He, T.; Chen, S.; Ni, B.; Gong, Y.; Wu, Z.; Song, L.; Gu, L.; Hu, W.; Wang, X. Water-Soluble Redox-Active Cage Hosting Polyoxometalates for Selective Desulfurization Catalysis. J. Am. Chem. Soc. 2018, 140, 4869-4876; Zirconium-Porphyrin-Based Metal-Organic Framework Hollow Nanotubes for Immobilization of Noble-Metal Single Atoms. Angew. Chem. Int. Ed 2018, 57, 3493-3498. (c) Mu, Y.; Wang, D.; Meng, X.-D.; Pan, J.; Han, S.-D.; Xue, Z.-Z. Construction of Iodoargentates with Diverse Architectures: Template Syntheses, Structures, and Photocatalytic Properties. Cryst. Growth Des. 2020, 20, $1130-1138$

(10) (a) Du, Z.-Y.; Zhang, L.; Wang, B.-Y.; Liu, S.-J.; Huang, B.; Liu, C.-M.; Zhang, W.-X. Two magnetic $\Delta$-chain-based Mn(ii) and Co(ii) coordination polymers with mixed carboxylate-phosphinate and $\mu 3$ OH-bridges. CrystEngComm 2017, 19, 1052-1057. (b) Liu, S.-J.; Cao, C.; Yao, S.-L.; Zheng, T.-F.; Wang, Z.-X.; Liu, C.; Liao, J.-S.; Chen, J.-L.; Li, Y.-W.; Wen, H.-R. Temperature- and vapor-induced reversible single-crystal-to-single-crystal transformations of three 2D/ 3D GdIII-organic frameworks exhibiting significant magnetocaloric effects. Dalton Trans. 2017, 46, 64-70. (c) Liu, S.-J.; Cao, C.; Xie, C.C.; Zheng, T.-F.; Tong, X.-L.; Liao, J.-S.; Chen, J.-L.; Wen, H.-R.; Chang, Z.; Bu, X.-H. Tricarboxylate-based GdIII coordination polymers exhibiting large magnetocaloric effects. Dalton Trans. 2016, 45, 9209-9215.

(11) (a) Kumar, M.; Wu, L.-H.; Kariem, M.; Franconetti, A.; Sheikh, H. N.; Liu, S.-J.; Sahoo, S. C.; Frontera, A. A Series of LanthanideBased Metal-Organic Frameworks Derived from Furan-2,5-dicarboxylate and Glutarate: Structure-Corroborated Density Functional Theory Study, Magnetocaloric Effect, Slow Relaxation of Magnetization, and Luminescent Properties. Inorg. Chem. 2019, 58, 77607774. (b) Yao, S.-L.; Liu, S.-J.; Tian, X.-M.; Zheng, T.-F.; Cao, C.; Niu, C.-Y.; Chen, Y.-Q.; Chen, J.-L.; Huang, H.; Wen, H.-R. A ZnIIBased Metal-Organic Framework with a Rare tcj Topology as a TurnOn Fluorescent Sensor for Acetylacetone. Inorg. Chem. 2019, 58, 3578-3581. (c) Li, R.-P.; Liu, Q.-Y.; Wang, Y.-L.; Liu, C.-M.; Liu, S.J. Evolution from linear tetranuclear clusters into one-dimensional chains of Dy(iii) single-molecule magnets with an enhanced energy barrier. Inorg. Chem. Front. 2017, 4, 1149-1156.

(12) (a) Zheng, X.-Y.; Kong, X.-J.; Zheng, Z.; Long, L.-S.; Zheng, L.S. High-Nuclearity Lanthanide-Containing Clusters as Potential Molecular Magnetic Coolers. Acc. Chem. Res. 2018, 51, 517-525. (b) Guo, F.-S.; Day, B. M.; Chen, Y.-C.; Tong, M.-L.; Mansikkamäki, A.; Layfield, R. A. A Dysprosium Metallocene Single-Molecule Magnet Functioning at the Axial Limit. Angew. Chem., Int. Ed. 2017, 56, 11445-11449. (c) Randall McClain, K.; Gould, C. A.; Chakarawet, K.; Teat, S. J.; Groshens, T. J.; Long, J. R.; Harvey, B. G. High-temperature magnetic blocking and magneto-structural correla- 
tions in a series of dysprosium(III) metallocenium single-molecule magnets. Chem. Sci. 2018, 9, 8492-8503.

(13) (a) Liu, J.-L.; Chen, Y.-C.; Tong, M.-L. Symmetry strategies for high performance lanthanide-based single-molecule magnets. Chem. Soc. Rev. 2018, 47, 2431-2453. (b) Zhu, Z.; Guo, M.; Li, X.-L.; Tang, J. Molecular magnetism of lanthanide: Advances and perspectives. Coord. Chem. Rev. 2019, 378, 350-364. (c) Jia, J.-H.; Li, Q.-W.; Chen, Y.-C.; Liu, J.-L.; Tong, M.-L. Luminescent single-molecule magnets based on lanthanides: Design strategies, recent advances and magneto-luminescent studies. Coord. Chem. Rev. 2019, 378, 365-381.

(d) Ling, Y.; Song, C.; Feng, Y.; Zhang, M.; He, Y. A metal-organic framework based on cyclotriphosphazene-functionalized hexacarboxylate for selective adsorption of $\mathrm{CO} 2$ and $\mathrm{C} 2 \mathrm{H} 6$ over $\mathrm{CH} 4$ at room temperature. CrystEngComm 2015, 17, 6314-6319.

(14) (a) Lochenie, C.; Schötz, K.; Panzer, F.; Kurz, H.; Maier, B.; Puchtler, F.; Agarwal, S.; Köhler, A.; Weber, B. Spin-Crossover Iron(II) Coordination Polymer with Fluorescent Properties: Correlation between Emission Properties and Spin State. J. Am. Chem. Soc. 2018, 140, 700-709. (b) Guo, F.-S.; Day, B. M.; Chen, Y.C.; Tong, M.-L.; Mansikkamäki, A.; Layfield, R. A. Magnetic hysteresis up to 80 kelvin in a dysprosium metallocene singlemolecule magnet. Science 2018, 362, 1400-1403. (c) Wang, J.; Feng, M.; Akhtar, M. N.; Tong, M.-L. Recent advance in heterometallic nanomagnets based on TMxLn4-x cubane subunits. Coord. Chem. Rev. 2019, 387, 129-153.

(15) (a) Su, J.; Hu, T.-H.; Murase, R.; Wang, H.-Y.; D'Alessandro, D. M.; Kurmoo, M.; Zuo, J.-L. Redox Activities of Metal-Organic Frameworks Incorporating Rare-Earth Metal Chains and Tetrathiafulvalene Linkers. Inorg. Chem. 2019, 58, 3698-3706. (b) Goodwin, C. A. P.; Ortu, F.; Reta, D.; Chilton, N. F.; Mills, D. P. Molecular magnetic hysteresis at 60 kelvin in dysprosocenium. Nature 2017, 548, 439-442. (c) Hu, P.; Yin, L.; Kirchon, A.; Li, J.; Li, B.; Wang, Z.; Ouyang, Z.; Zhang, T.; Zhou, H.-c. Magnetic Metal-Organic Framework Exhibiting Quick and Selective Solvatochromic Behavior along with Reversible Crystal-to-Amorphous-to-Crystal Transformation. Inorg. Chem. 2018, 57, 7006-7014.

(16) Blatov, V. A. IUCr CompComm Newsletter; IUCr, 2006; Vol. 7, p 4. see also. http://www.topos.ssu.samara.ru. 